\title{
Investigation on Low Hemoglobin and Ascaris Infection among Primary and Secondary School Students in Hohhot
}

\author{
Wentao Liu1 ${ }^{*}$, Bowei Dong1 ${ }^{*}$, Longxing Fan², Jun Liu³, Bao'an Ning4\#, Ying Liu1\# \\ ${ }^{1}$ School of Public Health, Inner Mongolia Medical University, Hohhot, China \\ ${ }^{2}$ Ministry of Education Key Laboratory for Analytical Science of Food Safety and Biology, Fujian Provincial Key Laboratory of \\ Analysis and Detection Technology for Food Safety, College of Chemistry, Fuzhou University, Fuzhou, China \\ ${ }^{3}$ The 291st Hospital of the Chinese People's Liberation Army, Baotou, China \\ ${ }^{4}$ Tianjin Institute of Environmental and Operational Medicine, Tianjin, China \\ Email: 1078308817@qq.com, "ningba@163.com, "yingruru@sina.com
}

How to cite this paper: Liu, W.T., Dong, B.W., Fan, L.X., Liu, J., Ning, B.A. and Liu, Y. (2020) Investigation on Low Hemoglobin and Ascaris Infection among Primary and Secondary School Students in Hohhot. Open Journal of Epidemiology, 10, 115-124. https://doi.org/10.4236/ojepi.2020.102010

Received: February 16, 2020

Accepted: April 4, 2020

Published: April 7, 2020

Copyright $\odot 2020$ by author(s) and Scientific Research Publishing Inc. This work is licensed under the Creative Commons Attribution International License (CC BY 4.0).

http://creativecommons.org/licenses/by/4.0/

\begin{abstract}
Introduction: Anemia and Ascaris infection are important indicators to reflect the health status of students. In this study, by investigating the current situation of low hemoglobin and positive rate of Ascaris eggs of primary and secondary school students in Hohhot, the health status of local primary and secondary school students is actually reflected. Objectives: To understand the prevalence of Low Hemoglobin and Ascaris infection among primary and secondary school students in Hohhot in 2015 and to give some suggestions on the health status of primary and secondary school students in Hohhot. Study Design: This project uses a cross-sectional study to investigate the distribution of disease and health status of primary and middle school students in Hohhot at a specific time, and to provide a clue to the cause of the hypothesis test. Methods: A stratified cluster random sampling method was used to select 4 districts, 4 counties and 1 flag in Hohhot, a total of 36 primary and secondary schools for sample survey. Cyanine $\mathrm{HiCN}$ and smear method is to detect hemoglobin and ascaris eggs positive. Results: In 2015, the positive rate of low hemoglobin in primary and secondary school students was $21.45 \%$ in urban and rural areas, $33.17 \%$ in urban and rural areas, $43.69 \%$ in rural areas, $13.59 \%$ in ascaris eggs, $10.69 \%$ in urban and rural areas, $7.81 \%$ in rural areas. There are geographical differences and gender differences between cities, urban-rural junctions and rural areas $(\mathrm{p}<0.05)$. Conclusion: The prevalence of low hemoglobin in primary and secondary school students in Hohhot is high in rural areas. The detection rate of ascaris egg positive rate in the city is high. Monitoring, publicity and education should continue to be strengthened.
\end{abstract}

*Bothauthors contributed equally to the writing of this article. 


\section{Keywords}

Primary and Secondary School Students, Low Hemoglobin, Ascaris Infection, Positive Rate

\section{Introduction}

Anemia and roundworm infection was included in 1992, The integrated control of students common diseases in the country plan [1], because of the physical development and the special nature of life and work, primary and secondary school students are prone to nutritional anemia. Roundworms are also relatively parasitic intestinal parasites that primary and secondary students are more susceptible to infection. Human infections can cause damage to the intestinal mucosa, malnutrition, allergies and other related symptoms. Ascaris infection varies from geographical environment, health condition, living habit, and investigation object. Both diseases are important indicators reflecting the health status of primary and secondary school students [2] [3] [4]. As the central city of the Inner Mongolia Autonomous Region, Hohhot has an area of 17,224 square kilometers. By the end of 2015, the city's resident population was 3.0596 million, of which the urban population was 206.49 million, the rural population was 994,700 , and the urbanization rate was 67.5\%, which was an important part of the Inner Mongolia Autonomous Region. The transportation hub is also an important center for economic, political, and cultural exchanges in the whole region. It can accurately represent the actual situation in the city by investigating the health indicators of urban and rural primary and secondary school students. This study investigated the status of the low hemoglobin and positive rate of Ascaris eggs in Han students of Han nationality in Hohhot in 2015, analyzed the factors that may cause differences, and provided corresponding intervention measures and recommendations.

\section{Methods}

\subsection{Object}

Hohhot administers 4 municipal districts (Huimin District, Yuquan District, Xincheng District, Saihan District), 4 counties (Tokto County, Qingshuihe County, Wuchuan County, and Helinge County) and 1 Flag (Tummer Left Banner). From March to July 2015, 160 primary and secondary school students in different sex age groups of 7, 9, 12, 14 and 17 years old were randomly selected from cities and villages to detect hemoglobin and Ascaris eggs in feces, respectively. Three hundred and thirty primary and middle school students in the sex 7, 9, 12, 14 and 17 years old groups were tested for hemoglobin and Ascaris eggs in feces, respectively [5] [6].

\subsection{Defining Standards for City, Urban-Rural Junction and Villages [7]}

The developed economy, good public infrastructure, convenient transportation, 
no agricultural land, residents mainly engaged in commerce, service industries and other industries are defined as cities. The economic development compared with the city lags behind, with the characteristics of urban-rural transition, residents living in urbanization, mainly engaged in non-agricultural industries, and the city's public facilities, residential facilities and other parts of the village-level area defined as the junction of urban and rural areas. The economic development is backward, the public infrastructure is poor, and the transportation is inconvenient. Most of them are agricultural land. The main income of the villagers comes from the definition of agricultural activities as rural areas.

\subsection{Methods}

1) Determination of hemoglobin One-time venous blood collection needles were used to collect 1 to $2 \mathrm{ml}$ of blood in the median vein of the student's elbow. The vacuum negative pressure tube with anticoagulant EDTA-2K was stored at room temperature and sent to the cooperating unit for hemoglobin measurement. The method of use was HiCN, and the instrument was Xenon Micron Automated Blood Analyzer xm-1000.

2) Determination of Ascaris Eggs Excrement using amniotic saline direct smear test.

3) The diagnostic criteria for hemoglobin adopt the WHO recommendation [8], see Table 1.

4) The diagnostic criteria for ascaris eggs were as follows: Microscopic examination of the ascarid eggs showed that eggs were positive for the ascarid eggs. If not, the results were negative.

\subsection{Statistical Analysis}

SPSS 22.0 statistical software was used for statistical analysis of the data. The count data was expressed as a percentage (positive rate). The 2 test was used. The test level was $\alpha=0.05, \mathrm{P}<0.05$ was considered statistically significant.

\section{Results}

\subsection{Low Hemoglobin Positive Findings}

The number of primary and secondary school students of Han nationalities in Hohhot was 1590 , low-hemoglobin positive was 359 , positive rate was $22.58 \%$, 3190 were actually examined at the urban-rural junction, and 1058 were positive

Table 1. Positive diagnostic criteria for low hemoglobin/(g/L).

\begin{tabular}{ccc}
\hline Age & Gender & Hemoglobin content \\
\hline $5-11$ years & Regardless of men and women & $<115 \mathrm{~g} / \mathrm{L}$ \\
$12-14$ years & Regardless of men and women & $<120 \mathrm{~g} / \mathrm{L}$ \\
$\geq 15$ years & Male & $<130 \mathrm{~g} / \mathrm{L}$ \\
& Female & $<120 \mathrm{~g} / \mathrm{L}$
\end{tabular}


for low hemoglobin, with a positive rate of $33.17 \%$. The actual number of people in rural areas was 1600, and 699 were positive for low hemoglobin, with a positive rate of $43.69 \%$. After statistical analysis, the positive rate of low hemoglobin was statistically different between cities, urban and rural areas, and rural areas $\left(\chi^{2}=160.312, \mathrm{P}<0.05\right)$. The two-segment method was used to further compare the rates of multiple samples. At this time, the test level was $\alpha=0.0125$, there was a difference between urban and rural areas $\left(\chi^{2}=57.031, \mathrm{P}<0.0125\right)$, and the difference between urban and rural villages $\left(\chi^{2}=160.312, \mathrm{P}<0.0125\right)$, rural and urban-rural splices. There were also differences between departments $\left(\chi^{2}=\right.$ $50.786, \mathrm{P}<0.0125)$. To sum up, the positive rate of low hemoglobin in primary and secondary school students in Hohhot was: rural $>$ urban-rural junction $>$ city (Table 2).

\subsubsection{Comparison of the Positive Rate of Low Hemoglobin between Different Genders}

According to Table 3, the positive rate of low hemoglobin in urban male in Hohhot primary school and middle school is $23.25 \%$, and that in female is $21.89 \%$. After statistical analysis, the positive rate of low hemoglobin is not statistically different between urban male and female $\left(\chi^{2}=0.191, \mathrm{P}>0.05\right)$; male and female low-hemoglobin positive rate was $31.62 \%$ in urban and rural areas, female were $34.71 \%$, after statistical analysis, low-hemoglobin positive rate in the rural-urban junction male and female sex was not statistically significant $\left(\chi^{2}=\right.$ 3.440, $\mathrm{P}>0.05$ The positive rate of low-hemoglobin in rural male was $40.00 \%$ and that in female was $43.68 \%$. After statistical analysis, the positive rate of low-hemoglobin was statistically different between rural male and female $\left(\chi^{2}=\right.$ 8.843, $\mathrm{P}<0.05)$.

Table 2. Comparison of low hemoglobin areas in primary and secondary school students in Hohhot.

\begin{tabular}{cccc}
\hline Area & Number of people examined & Positive number & Positive rate (\%) \\
\hline City & 1590 & 359 & 22.58 \\
Urban-rural junction & 3190 & 1058 & 33.17 \\
Rural & 1600 & 699 & 43.69 \\
Total & 6380 & 2098 & 32.88 \\
\hline
\end{tabular}

Table 3. Comparison between different sexes of low hemoglobin in primary and middle school students in Hohhot.

\begin{tabular}{|c|c|c|c|c|c|c|c|c|c|c|c|c|c|c|c|}
\hline \multirow[b]{2}{*}{ Gender } & \multicolumn{3}{|c|}{ Urban Low Hemoglobin } & \multirow[b]{2}{*}{$x^{2}$} & \multirow[b]{2}{*}{$\mathrm{p}$} & \multicolumn{3}{|c|}{$\begin{array}{c}\text { Urban and rural junction low } \\
\text { hemoglobin }\end{array}$} & \multirow[b]{2}{*}{$x^{2}$} & \multirow[b]{2}{*}{$\mathrm{P}$} & \multicolumn{3}{|c|}{ Rural Low Hemoglobin } & \multirow[b]{2}{*}{$x^{2}$} & \multirow[b]{2}{*}{$\mathrm{P}$} \\
\hline & $\begin{array}{l}\text { Number } \\
\text { of people } \\
\text { surveyed }\end{array}$ & $\begin{array}{l}\text { Positive } \\
\text { number }\end{array}$ & $\begin{array}{l}\text { Positive } \\
\text { rate }(\%)\end{array}$ & & & $\begin{array}{l}\text { Number } \\
\text { of people } \\
\text { surveyed }\end{array}$ & $\begin{array}{l}\text { Positive } \\
\text { number }\end{array}$ & $\begin{array}{l}\text { Positive } \\
\text { rate }(\%)\end{array}$ & & & $\begin{array}{l}\text { Number } \\
\text { of people } \\
\text { surveyed }\end{array}$ & $\begin{array}{l}\text { Positive } \\
\text { number }\end{array}$ & $\begin{array}{l}\text { Positive } \\
\text { rate }(\%)\end{array}$ & & \\
\hline Male & 800 & 186 & 23.25 & 0.415 & 0.519 & 1600 & 506 & 31.62 & 3.440 & 0.064 & 800 & 320 & 40.00 & 8.843 & 0.003 \\
\hline Female & 790 & 173 & 21.89 & & & 1590 & 552 & 34.71 & & & 800 & 379 & 43.68 & & \\
\hline Total & 1590 & 359 & 22.58 & & & 3190 & 1058 & 33.17 & & & 1600 & 699 & 43.69 & & \\
\hline
\end{tabular}




\subsubsection{Comparison of the Positive Rate of Low Hemoglobin among Different Ages}

As shown in Table 4, a statistical analysis of low-level hemoglobin levels in primary and secondary school students in Hohhot City shows that there are statistical differences between age groups $\left(\chi^{2}=73.299, \mathrm{P}<0.05\right)$. The statistical analysis was performed on the low-hemoglobin levels in the urban-rural junctions and rural primary and middle school students respectively. There were also statistical differences between the age groups $\left(\chi^{2}=242.693, \mathrm{P}<0.05\right.$ and $\chi^{2}=$ $200.379, \mathrm{P}<0.05)$. Bonferroni was further used. After calibration, there were no statistical differences between the low age group ( 7 years and 9 years old), but there was a statistically significant difference between the low age group and other age groups, combined with a low hemoglobin positive rate. It can be seen that the positive rate in the low age group ( 7,9 years old) is often higher than other age groups.

\subsection{Ascaris Eggs Positive Survey Results}

The number of primary and secondary school students of Han nationality in Hohhot was 1590 , and the number of positive ascaris eggs was 216 . The positive rate was $13.59 \%$. The actual number of people in the urban-rural junction was 3190 , and the number of positive ascaris eggs was 341 . The positive rate was $10.69 \%$. The actual number of people in rural areas was 1600 , and the number of positive ascaris eggs was 125 . The positive rate was $7.81 \%$. After statistical analysis, there was a statistically significant difference in the positive rate of ascaris eggs among city, rural and rural areas, and rural areas $\left(\chi^{2}=26.475, \mathrm{P}<0.05\right)$. The selective $\chi^{2}$ segmentation method was used to further compare the multiple sample rates. At this time, the test level was $\alpha=0.0125$, there was a difference between the urban and rural areas $\left(\chi^{2}=7.754, \mathrm{P}<0.0125\right)$, the difference between the urban and rural villages $\left(\chi^{2}=26.54, \mathrm{P}<0.0125\right)$, rural and urban-rural junctions There was also a difference between them $\left(\chi^{2}=10.044, \mathrm{P}<0.0125\right)$. To sum up, the positive rates of ascaris eggs in secondary and primary school students in Hohhot were city $>$ urban-rural junction $>$ rural (Table 5).

Table 4. Survey of low hemoglobin levels in primary and secondary school students in Hohhot.

\begin{tabular}{cccccccccc}
\hline & \multicolumn{3}{c}{ City } & \multicolumn{3}{c}{ Urban and rural junction } & \multicolumn{3}{c}{ Rural } \\
\cline { 2 - 9 } Age & $\begin{array}{c}\text { Number } \\
\text { of people } \\
\text { examined }\end{array}$ & $\begin{array}{l}\text { Positive } \\
\text { number }\end{array}$ & $\begin{array}{c}\text { Positive } \\
\text { rate (\%) }\end{array}$ & $\begin{array}{c}\text { Number } \\
\text { of people } \\
\text { examined }\end{array}$ & $\begin{array}{c}\text { Positive } \\
\text { number }\end{array}$ & $\begin{array}{c}\text { Positive } \\
\text { rate (\%) }\end{array}$ & $\begin{array}{c}\text { Number } \\
\text { of people } \\
\text { examined }\end{array}$ & $\begin{array}{c}\text { Positive } \\
\text { number }\end{array}$ & $\begin{array}{c}\text { Positive } \\
\text { rate }\end{array}$ \\
\hline 7 & 319 & 91 & $28.53 \%$ & 639 & 298 & $46.64 \%$ & 320 & 207 & $64.69 \%$ \\
9 & 320 & 115 & $35.94 \%$ & 640 & 314 & $49.06 \%$ & 320 & 199 & $62.19 \%$ \\
12 & 320 & 60 & $18.75 \%$ & 640 & 195 & $30.47 \%$ & 320 & 135 & $42.19 \%$ \\
14 & 312 & 62 & $19.87 \%$ & 632 & 154 & $24.37 \%$ & 320 & 92 & $28.75 \%$ \\
17 & 319 & 31 & $9.72 \%$ & 639 & 97 & $15.18 \%$ & 320 & 66 & $20.63 \%$ \\
\hline
\end{tabular}


Table 5. Comparison of ascaris egg positive areas of primary and secondary school students in Hohhot.

\begin{tabular}{cccc}
\hline Area & Number of people examined & Positive number & Positive rate (\%) \\
\hline City & 1590 & 216 & 13.59 \\
Urban-rural junction & 3190 & 341 & 10.69 \\
Rural & 1600 & 125 & 7.81 \\
Total & 6380 & 682 & 10.69 \\
\hline
\end{tabular}

\subsubsection{Comparison of Positive Rate of Ascaris Eggs between Different Sex Populations}

From Table 6, it can be seen that the positive rate of male ascaris eggs in primary and secondary schools in Hohhot is $15.50 \%$ and that in females is $11.64 \%$. After statistical analysis, there was statistical difference between male and female sex in the city $\left(\chi^{2}=5.030, \mathrm{P}<0.05\right)$. The positive rate of male ascaris was $11.93 \%$ and $9.43 \%$ in females. After statistical analysis, there was a statistically significant difference in the male and female sex ratios between urban and rural areas $\left(\chi^{2}=\right.$ 5.236, $\mathrm{P}<0.05$ ). The positive rate of males was $8.37 \%$ and $7.25 \%$ in females. Statistical analyses were performed. The positive rate of ascaris eggs was not statistically different between rural males and females $\left(\chi^{2}=0.703, \mathrm{P}>0.05\right)$.

\subsubsection{Comparison of Positive Rate of Ascaris Eggs between Different Ages}

As shown in Table 7, a statistical analysis of the positive rate of ascaris eggs among primary and secondary school students in Hohhot city shows that there is no statistical difference between age groups $\left(\chi^{2}=5.982, \mathrm{P}>0.05\right)$. The statistical analysis was performed on the positive rate of ascaris eggs in the urban-rural junctions and in primary and secondary school students in rural areas. There was no statistical difference between age groups $\left(\chi^{2}=6.144, \mathrm{P}>0.05\right.$ and $\left.\chi^{2}=6.856, \mathrm{P}>0.05\right)$.

\section{Discussion}

The age distribution of the data is well-represented. The age of 7 is the majority of primary school children in China, at this time, children are in prepuberty. The age of 9 represents the early period of puberty, after which children begin to gradually enter puberty and secondary sexual characteristics begin to appear. At the age of 12 , female gradually began menarche, and male entered the peak of growth. $14-17$ years of age are the mid-term and late-stage of adolescence. The growth of basic sexual maturity of secondary sexual characteristics is stopped and female begin to have periodic menstruation [9].

The reason why the positive rate of urban low-height hemoglobin in urban and rural areas and rural areas is likely to increase sequentially is that the nutritional status of the three places is relatively different, and the urban nutrition status is better than that in urban and rural areas. The health care status and health care knowledge between three areas may also be the reason for the difference 
Table 6. Comparison of male and female ascaris eggs positive sexuality in primary and secondary school students in Hohhot.

\begin{tabular}{|c|c|c|c|c|c|c|c|c|c|c|c|c|c|c|c|}
\hline \multirow[b]{2}{*}{ Gender } & \multicolumn{3}{|c|}{$\begin{array}{l}\text { Infection of Ascaris Ascaris } \\
\text { in city }\end{array}$} & \multirow[b]{2}{*}{$x^{2}$} & \multirow[b]{2}{*}{$\mathrm{P}$} & \multicolumn{3}{|c|}{$\begin{array}{l}\text { Infection of Ascaris Ascaris } \\
\text { in urban and rural junction }\end{array}$} & \multirow[b]{2}{*}{$x^{2}$} & \multirow[b]{2}{*}{$\mathrm{P}$} & \multicolumn{3}{|c|}{$\begin{array}{c}\text { Infection of Ascaris Ascaris } \\
\text { in rural areas }\end{array}$} & \multirow[b]{2}{*}{$x^{2}$} & \multirow[b]{2}{*}{$\mathrm{P}$} \\
\hline & $\begin{array}{l}\text { Number } \\
\text { of people } \\
\text { surveyed }\end{array}$ & $\begin{array}{l}\text { Positive } \\
\text { number }\end{array}$ & $\begin{array}{l}\text { Positive } \\
\text { rate }(\%)\end{array}$ & & & $\begin{array}{l}\text { Number } \\
\text { of people } \\
\text { surveyed }\end{array}$ & $\begin{array}{l}\text { Positive } \\
\text { number }\end{array}$ & $\begin{array}{l}\text { Positive } \\
\text { rate }(\%)\end{array}$ & & & $\begin{array}{l}\text { Number } \\
\text { of people } \\
\text { surveyed }\end{array}$ & $\begin{array}{l}\text { Positive } \\
\text { number }\end{array}$ & $\begin{array}{l}\text { Positive } \\
\text { rate (\%) }\end{array}$ & & \\
\hline Male & 800 & 124 & 15.50 & 5.030 & 0.025 & 1600 & 191 & 11.93 & 5.236 & 0.022 & 800 & 67 & 8.37 & 0.703 & 0.402 \\
\hline Female & 790 & 92 & 11.64 & & & 1590 & 150 & 9.43 & & & 800 & 58 & 7.25 & & \\
\hline Total & 1590 & 216 & 13.59 & & & 3190 & 341 & 10.69 & & & 1600 & 125 & 7.81 & & \\
\hline
\end{tabular}

Table 7. Positive survey of ascaris eggs in middle and primary school students in Hohhot.

\begin{tabular}{cccccccccc}
\hline & \multicolumn{3}{c}{ City } & \multicolumn{3}{c}{ Urban and rural junction } & \multicolumn{3}{c}{ Rural } \\
\cline { 2 - 10 } Age & $\begin{array}{c}\text { Number } \\
\text { of people } \\
\text { examined }\end{array}$ & $\begin{array}{c}\text { Positive } \\
\text { number }\end{array}$ & $\begin{array}{c}\text { Positive } \\
\text { rate (\%) }\end{array}$ & $\begin{array}{c}\text { Number } \\
\text { of people } \\
\text { examined }\end{array}$ & $\begin{array}{l}\text { Positive } \\
\text { number }\end{array}$ & $\begin{array}{c}\text { Positive } \\
\text { rate (\%) }\end{array}$ & $\begin{array}{c}\text { Number } \\
\text { of people } \\
\text { examined }\end{array}$ & $\begin{array}{c}\text { Positive } \\
\text { number }\end{array}$ & $\begin{array}{c}\text { Positive } \\
\text { rate (\%) }\end{array}$ \\
\hline 7 & 319 & 42 & $13.17 \%$ & 639 & 72 & $11.27 \%$ & 320 & 30 & $9.38 \%$ \\
9 & 320 & 39 & $12.19 \%$ & 640 & 54 & $8.44 \%$ & 320 & 15 & $4.69 \%$ \\
12 & 320 & 37 & $11.56 \%$ & 640 & 64 & $10.00 \%$ & 320 & 27 & $8.44 \%$ \\
14 & 312 & 42 & $13.46 \%$ & 632 & 72 & $11.39 \%$ & 320 & 30 & $9.38 \%$ \\
17 & 319 & 56 & $17.55 \%$ & 639 & 79 & $12.36 \%$ & 320 & 23 & $7.19 \%$ \\
\hline
\end{tabular}

of nutritional status between the three places. City schools will regularly do physical examination, grasp the health status of students in time, and provide timely intervention for students' health.

Because the traditional diet in China is mainly based on plant foods. The intake of meat and soy products is relatively low, leading to inadequate intake of high quality protein, which is hard to meet the iron demand of the body, and is easy to cause iron deficiency anemia. This phenomenon is particularly evident in rural areas. In addition, due to differences in eating habits between male and female, female are more likely to experience partial eclipse, picky eaters, etc. in their daily lives. At the same time, because the physiological conditions of male and female are different after the primary and secondary students enter puberty, the male enter the peak period of growth and development, and the body's nutrients. The demand for menstruation has greatly increased, and the occurrence of menarche, menstruation, etc. in female may also be responsible for the difference in the male-to-female low-hemoglobin positive rate in the $12-14$ age group [10] [11].

The positive rate of ascaris eggs in villages, urban-rural junctions, and urban ascaris increased in turn. This may lead to differences in the ascaris egg positive rates among the three populations. This may be due to differences in dietary habits in the three places. Rural areas have fewer opportunities to access snacks other than dinner, and less contact with "roadside stalls" on the street's "three-nothing" products than rural-rural junctions and cities. Therefore, stu- 
dents in rural areas are more likely to combine urban and rural areas. The positive rate of ascaris eggs in the department and city locusts was relatively low. At the same time eating habits may be the cause of gender differences between male and female in urban and rural areas.

\section{Conclusion}

In this paper, we draw attention to the positive rate of low hemoglobin in primary and secondary school students was $21.45 \%$ in urban and rural areas, $33.17 \%$ in urban and rural areas, $43.69 \%$ in rural areas, $13.59 \%$ in ascaris eggs, $10.69 \%$ in urban and rural areas, $7.81 \%$ in rural areas. There are geographical differences and gender differences between cities, urban-rural junctions and rural areas $(\mathrm{p}<0.05)$. The prevalence of low hemoglobin in primary and secondary school students in Hohhot is high in rural areas. The detection rate of ascaris egg positive rate in the city is high. Monitoring, publicity and education should continue to be strengthened.

\section{Suggestion}

In response to the investigation of the health status of primary and secondary school students in Hohhot, the following preventive health measures are proposed:

1) The school regularly organizes students to conduct health checks to keep abreast of the students' health status.

2) Promote knowledge of nutrition and health education in schools, promote reasonable diets, and strengthen the education of eating habits and hygiene habits. Promoting a proper diet can not only effectively improve the situation of low hemoglobin in primary and middle school students; the locust infection is closely related to the living environment and hygiene habits of primary and secondary school students [12], strengthens the hygienic habits of preaching work, and develops hand washing before meals. The regular cutting of nails can reduce the positive rate of aphids. In addition, it can also reduce the positive rate of aphid eggs examination by taking anthelmintic drugs [13].

3) Organize students to carry out extra-curricular activities and physical exercises to improve students' physical fitness.

4) The prevention and control of low hemoglobin should start from elementary schools, especially in rural schools, and use reasonable diets, maintain nutritional balance, and conduct health education [8].

\section{Ethical Approval}

Ethical approval was not required for this study because it is based on fully anonymous secondary data.

\section{Funding}

None declared. 


\section{Author Contributions}

Liu Ying and Liu Wentao conceived and designed the study, performed statistical analyses, and drafted the article. All other coauthors participated in the conception of the study, interpreted the data, revised the analyses critically, and approved the final version of the article.

\section{Conflicts of Interest}

The authors have no conflicts of interest to declare.

\section{References}

[1] Department of Health Supervision of the Ministry of Health, School of Sports and Health of the State Education Commission, National Patriotic Health Committee (1992) National Comprehensive Control Program for Common Diseases.

[2] Hua, H., Yang, H.F. and Ding, J.G. (2001) Investigation and Analysis of 413 Anthrax and Aphid Eggs Infection among Primary and Middle School Students. Chinese Journal of Coal Industry Medicine, No. 9, 714.

[3] Yang, W.G. and Zhang, Y. (2009) Investigation of Anemia and Aphid Infection among Primary and Secondary School Students in Tianshui City. Chinese Journal of School Health, 30, 620-621.

[4] Li, L.Z., Mai, M.T., Qiao, W.C., Wang, H., Zhang, J., Liu, L.H., Assi, A. and Aniva, M. (2009) Evaluation of the Effect of Nutrition Education on Prevention of Iron Deficiency Anemia in Children and Adolescents. School Health in China, 30, 985-987.

[5] Liu, Y., Fan, L.X., Qu, X.C., et al. (2016) The Prevalence of Dental Caries among Urban and Rural Pupils in Hohhot. Chinese Journal of School Health, 37, 1851-1855.

[6] Duan, J.L., Zeng, X.B., Sun, Y., Teng, L.X., Lv, R.R. and Zhao, H. (2012) Analysis of the Prevention and Treatment of Tsutsugamushi Disease in Primary and Middle School Students in Beijing. Chinese Journal of School Health, 33, 438-439.

[7] Du, L.J. (2011) Discussion on How to Perform High-Quality Urban-Rural Division Work Statistics. China Urban Economy, No. 27, 284.

[8] WHO. Haemoglobin Concentrations for the Diagnosis of Anaemia and Assessment of Severity.

http://apps.who.int/iris/bitstream/10665/85839/3/WHO NMH NHD MNM 11.1 eng.pdf?ua $=1$

[9] Ji, C.Y. (2008) The Status and Degree of Anemia among Primary and Secondary School Students in China. Chinese Journal of School Health, No. 2, 111-113.

[10] Wang, Z.Y., Ma, A.Q., Xu, D.Y., et al. (2003) Comparison of Hemoglobin and Anemia in Male and Female Students after Adolescence. Journal of Hygiene Research, 32, 144-146.

[11] Zhang, H., Zhang, Y.Q., Li, H., et al. (2014) Adolescent Growth Spurt in Girls and Its Relationship with Sexual Development. Chinese Journal of Evidence Based Pediatrics, 9, 107-111.

[12] Xu, H.F., Nie, S.P., Meng, R.L., Xu, Y. and Xia, L. (2012) Status of Anaemia and 
Mite Infection in Primary and Middle School Students in Guangdong Province in 2010. Chinese Journal of School Health, 33, 846-848.

[13] Li, J.J. and Zhang, Y.H. (1995) Investigation Report on Ascaris Egg Infection among Pupils in Urban and Rural Areas of Heihe City. 